\title{
Accumulation of Pro-Cancer Cytokines in the Plasma Fraction of Stored Packed Red Cells
}

\author{
Douglas D. Benson, \\ Denver Health Medical Center, 777 Bannock St., Denver, CO 80204-0206, USA. Department of \\ Surgery, University of Colorado, Aurora, CO, USA
}

Adam W. Beck, University of Texas-Southwestern Medical Center, Dallas, TX, USA

Marie S. Burdine, University of Texas-Southwestern Medical Center, Dallas, TX, USA

Rolf Brekken, University of Texas-Southwestern Medical Center, Dallas, TX, USA

Christopher C. Silliman, and

Department of Surgery, University of Colorado, Aurora, CO, USA. Bonfils Blood Center, Denver, CO, USA

Carlton C. Barnett Jr

Denver Health Medical Center, 777 Bannock St., Denver, CO 80204-0206, USA. Department of Surgery, University of Colorado, Aurora, CO, USA. Bonfils Blood Center, Denver, CO, USA

Carlton C. Barnett: carlton.barnett@dhha.org

\section{Abstract}

Introduction-Perioperative blood transfusion has been linked to decreased survival in pancreatic cancer; however, the exact causal mechanism has not been elucidated. Allogeneic transfusions are known to expose patients to foreign cells and lipid mediators. We hypothesize that stored packed red cells (pRBCs) contain pro-cancer cytokines that augment tumor progression. We analyzed the plasma fraction of stored pRBCs for pro-cancer cytokines and evaluated the affect of both storage time and leukocyte reduction on these mediators.

Methods-Chemiarray ${ }^{\mathrm{TM}}$ analysis for pro-cancer cytokines was performed on the acellular plasma fraction of stored leukocyte-reduced (LR) and non-leukocyte-reduced (NLR) pRBCs at day 1 (D.1-fresh) and day 42 (D.42-outdate) of storage. Elevated expression of monocyte chemotactic protein-1 (MCP-1), regulated on activation, normal $\mathrm{T}$ cell expressed and secreted (RANTES), angiogenin, tumor necrosis factor-alpha (TNF-a), epidermal growth factor (EGF), and platelet-derived growth factor (PDGF) was found. Specific enzyme-linked immunosorbent assay was performed for each of these factors in LR and NLR blood at D.1, day 28, and D.42. Data were analyzed by ANOVA. A $p$ value $₫ .05$ was considered significant; $N \geq 4$ per group. Migration assays were performed using inhibitors of EGF (gefitinib) and PDGF (imatinib) on murine pancreatic adenocarcinoma cells (Pan02) exposed to D.1 and D.42 LR and NLR plasma. Proliferation assays were performed on Pan02 cells to test the inhibition of PDGF.

(C) 2012 The Society for Surgery of the Alimentary Tract

Correspondence to: Carlton C. Barnett, Jr, carlton . barnett @dhha . org.

This manuscript was presented at the Society for Surgery of the Alimentary Tract, May 10, 2011, in Chicago, IL. 
Results-MCP-1 levels increased with storage time in LR blood, $86.3 \pm 6.3 \mathrm{pg} / \mathrm{ml}$ at D.1 vs. $121.2 \pm 6.1 \mathrm{pg} / \mathrm{ml}$ at D.42 ( $p=0.007)$, and NLR blood, $78.2 \pm 7.3 \mathrm{pg} / \mathrm{ml}$ at D. 1 vs. $647.8 \pm 220.7 \mathrm{pg} / \mathrm{ml}$ at D.42 ( $p=0.02$ ). RANTES levels are lower in LR compared to NLR stored blood, $3.0 \pm 1.9$ vs. $15.8 \pm 0.7 \mathrm{pg} / \mathrm{ml}$ at D.42 ( $p<0.001)$, but similar in D. 1 blood, $13.8 \pm 1.8 \mathrm{pg} / \mathrm{ml}$ in LR vs. $12.0 \pm 1.6 \mathrm{pg} /$ $\mathrm{ml}$ in NLR. Angiogenin levels were different between LR and NLR blood, $0 \mathrm{pg} / \mathrm{ml}$ (undetectable) vs. $44.2 \pm 3.7 \mathrm{pg} / \mathrm{ml}(p<0.001)$. Storage time did not affect concentration. TNF-a levels were not different between LR and NLR blood, and there was no storage time effect on concentration. EGF and PDGF levels increased with storage time in NLR blood only, $216.4 \pm 3.8 \mathrm{pg} / \mathrm{ml}$ at D. $1 \mathrm{vs.}$ $1,436.4 \pm 238.6 \mathrm{pg} / \mathrm{ml}$ at D.42 for EGF ( $p=0.001)$, and $61.6 \pm 6.0 \mathrm{pg} / \mathrm{ml}$ at D. $1 \mathrm{vs} .76 .5 \pm 1.7 \mathrm{pg} / \mathrm{ml}$ at D.42 $(p=0.003)$ for PDGF. Inhibition of EGF reduced migration in Pan02 cells treated with D.42 NLR blood, $245.9 \pm 11.2$ vs. $164.6 \pm 10.6$ cells/hpf $(p<0.001)$. Inhibition of PDGF had no effect on Pan02 migration and reduced cell proliferation in cells treated with D.42 NLR, 181.1 $\pm 1.5 \%$ over control vs. $157.5 \pm 2.1 \%(p<0.001)$.

Conclusion-Pro-cancer cytokines that can augment tumor progression were identified in pRBCs. Some of these factors are present in fresh blood. The soluble factors identified herein may represent possible therapeutic targets to offset negative effects of transfusion. These data stress the need for efforts in cancer patients to reduce transfusion requirements if needed.

\section{Keywords}

Transfusion; Cancer; Storage lesion; Cytokines

\section{Introduction}

The majority of studies on perioperative blood transfusion in cancer patients have linked transfusion to adverse outcomes and decreased survival. ${ }^{1-7}$ Although a direct causal mechanism has not been elucidated, blood transfusion has been shown to induce anergy, Tsuppressor cells, and clonal deletion. ${ }^{8}$ Underlying clinical variables surrounding the need for blood transfusion likely confound patient outcomes and interpretation of results. Our lab has shown that the acellular fraction of packed red cells (pRBCs) increases tumor cell proliferation and migration in vitro and augments pancreas cancer progression in vivo in an immunocompetent model of murine pancreatic adenocarcinoma. ${ }^{9-11}$ Interestingly, in vitro proliferation and migration increased with storage time, while augmented in vivo growth was evident with fresh blood, indicating pro-cancer mediators may be present in fresh (day 1) blood. ${ }^{9}$

Transfusion is a known risk factor for acute lung injury ${ }^{12}$ and a major independent risk factor for post-injury multiple organ failure following both massive and less severe trauma. ${ }^{13}$ During storage, plasma from pRBCs accumulates lipid mediators, which prime neutrophils, and have been implicated in transfusion-related acute lung injury. ${ }^{14-17}$ Transfusion of older blood is also associated with increased infections in severely injured patients. ${ }^{18}$ Additionally, receipt of blood products has been linked to more infectious complications and mortality in cardiac surgery patients. ${ }^{8,19}$ It has been hypothesized that the negative effects of blood transfusion may be mediated by "passenger leukocytes," which release granules, anti-leukocyte and anti-HLA antibodies, apoptotic bodies, and other soluble mediators. ${ }^{20-22}$ However, clinical studies comparing leukocyte-reduced (LR) pRBCs versus non-leukoreduced (NLR) pRBCs have not demonstrated survival advantage with transfusion in patients with colorectal cancers. ${ }^{22-24}$ We hypothesize that stored packed red blood cells contain pro-cancer cytokines that augment tumor progression, and these soluble mediators increase with storage time and are attenuated with prestorage leukoreduction. 


\section{Materials and Methods}

\section{Blood}

Following a protocol approved by the Colorado Multi-institutional Review Board, consent was obtained and ten healthy donors donated $450 \mathrm{~mL}$ of whole blood per American Association of Blood Banks criteria. ${ }^{25}$ Preparation of the acellular fraction of pRBCs has been described previously. ${ }^{9}$

\section{Protein Expression in Stored pRBCs}

Chemiarray ${ }^{\mathrm{TM}}$ Human Cytokine Antibody Array III Map (Chemicon International, Billerica, MA) analysis was used to investigate the expression of pro-cancer cytokines and growth factors in the acellular fraction of LR and NLR of day 1 (D.1) and day 42 (D.42) pRBCs. Aliquots of the acellular fraction of each tested unit of pRBCs were applied to the membranes according to the manufacturers' instructions. Dulbecco's minimal essential medium (DMEM, Invitrogen, Carlsbad, CA) was also analyzed as a negative control. Chemiluminescent images were acquired using a FlourChem ${ }^{\mathrm{TM}}$ imaging system (Alpha Innotech, Santa Clara, CA).

\section{Enzyme-linked Immunosorbent Assay}

ChemiArray ${ }^{\mathrm{TM}}$ analysis revealed increased expression of monocyte chemotactic protein-1 (MCP-1), regulated on activation, normal T cell expressed and secreted (RANTES), angiogenin, tumor necrosis factor-alpha (TNF-a), epidermal growth factor (EGF), and platelet-derived growth factor BB (PDGF-BB). To evaluate the concentrations of each of these soluble factors in stored pRBCs, separate aliquots of the acellular fraction of LR and NLR pRBCs from D.1, day 28 (D.28), and D.42 were quantified with enzyme-linked immunosorbent assay (ELISA) following the manufacturer's instructions. ELISAs for MCP-1, RANTES, angiogenin, TNF-a, EGF, and PDGF-BB were purchased from R\&D Systems (Minneapolis, MN).

\section{Pan02 Cell Culture}

The murine pancreatic adenocarcinoma line, Pan02, was obtained from the Developmental Therapeutics Program, NCI (Frederick, MD). Cells were maintained at $37^{\circ} \mathrm{C}$ in a mixture of $5 \% \mathrm{CO}_{2}$ and $95 \%$ air in DMEM supplemented with $10 \%$ fetal bovine serum (FBS; Gemini Bio-Products, Woodland, CA) and 1\% penicillin-streptomycin (Invitrogen).

\section{Migration Assay}

Migration assays were performed using commercially available inhibitors of EGF, gefitinib (Iressa; AstraZeneca, Wilmington, DE) or PDGF, imatinib (Gleevec; Novartis, New York, NY). Pan02 cells were harvested into DMEM alone and loaded into the upper chamber of a Cultrex BME (Trevigen Inc., Gaithersburg, MD) Matrigel-coated 8- $\mu$ m modified Boyden chamber insert (Becton Dickinson Labware, Franklin Lakes, NJ) with experimental media in the lower chamber, which contained the following reagents: DMEM alone (control), DMEM plus; D. 1 LR and NLR plasma fraction of pRBCs with or without additional treatment with gefitinib or imatinib, and D.42 LR and NLR plasma of pRBCs with or without additional treatment with gefitinib or imatinib. Cells were kept at $37^{\circ} \mathrm{C}$ for $24 \mathrm{~h}$. Membranes were then stained, excised, mounted on slides, and examined by using a Nikon inverted microscope (Eclipse E600; Nikon, Tokyo, Japan) at $\times 200$ total magnification. Cell migration across the membrane was quantified in five to ten fields of view for each membrane, with two membranes for each treatment condition. For assays done with gefitinib, the inhibitor was added to the supernatant to create a concentration of $10 \mu \mathrm{g} / \mathrm{ml}$ and allowed to incubate for 1 $\mathrm{h}$ in the bottom chamber of the 24 -well dish prior to cells being added to the insert. For 
assays done with imatinib, the inhibitor was added to the supernatant to create a concentration of $1 \mu \mathrm{g} / \mathrm{ml}$ and allowed to incubate for $1 \mathrm{~h}$ hour in the bottom chamber of the 24-well dish prior to cells being added to the insert. Data are presented as the mean number of cells that migrated across the membrane for each high-powered field (total magnification, $\times 200)$.

\section{Proliferation Assay}

Proliferation assays were also performed using imatinib. Cultured Pan02 cells were harvested using 1\%Trypsin-EDTA (Invitrogen). The cells were placed in 96-well dishes (Falcon; BD Biosciences, San Jose, CA) in DMEM+10\% FBS for $6 \mathrm{~h}$ to allow cells to adhere. Media were then removed, and experimental media were added with various conditions as follows: DMEM alone (control), DMEM+10\% D.1 or D. 42 from both LR and NLR plasma from pRBCs with or without additional treatment with imatinib. Cell proliferation was determined in triplicate at $24 \mathrm{~h}$ by using a commercially available MTS assay (CellTiter 96 Aqueous One Solution Cell Proliferation Assay; Promega Corporation, Madison, WI, Cat. No. G3580) according to the manufacturers' guidelines, and absorbance was quantified using a FLUOstar OPTIMA plate reader (BMG Lab-Tech, Offenburg, Germany). For assays done with imatinib, the inhibitor was added to the supernatant at a concentration of $1 \mu \mathrm{g} / \mathrm{ml}$. Data are presented as a percentage of control (DMEM alone).

\section{Statistical Analysis}

Statistical analysis was by analysis of one-way variance using a post hoc Fisher's exact test. Statistical significance was accepted as $p$ values less than 0.05 . All numerical data are presented as means \pm standard error. $N \geq 4$ per group.

\section{Results}

\section{Increased Expression of Pro-Cancer Mediators in Stored pRBCs}

Screening ChemiArray Human Cytokine Antibody Array III Map analysis for growth and inflammatory mediators present in the plasma fraction of D.1 and D. 42 pRBCs, LR, and NLR showed increased expression of MCP-1, RANTES, angiogenin, TNF-a, EGF, and PDGF-BB (Fig. 1).

\section{Effects of Storage Time and Leukocyte Reduction on Pro-Cancer Mediators in pRBCs}

MCP-1-Quantitative analysis of the concentration of MCP-1 in the plasma fraction of pRBCs is shown in Fig. 2a. MCP-1 levels increase with storage time in both LR and NLR blood. MCP-1 levels in D.1 LR blood, $86.3 \pm 6.3 \mathrm{pg} / \mathrm{ml}$, increase with storage time to $121.2 \pm 6.1 \mathrm{pg} / \mathrm{ml}$ in D.42 LR blood ( $p=0.007)$. Levels increase at a greater rate in NLR blood, $78.2 \pm 7.3 \mathrm{pg} / \mathrm{ml}$ in D.1 NLR blood to $647.8 \pm 220.7 \mathrm{pg} / \mathrm{ml}$ in D.42 NLR blood $(p=0.02)$. By D.42, there was a higher level of MCP-1 in NLR vs. LR blood, 647.8 \pm 220.7 vs. $121.2 \pm 6.1 \mathrm{pg} / \mathrm{ml}$, respectively, $(p=0.05)$.

RANTES-RANTES levels in the plasma fraction of pRBCs are shown in Fig. 2b. In LR blood, RANTES levels decrease with storage time. D.1 levels, $13.8 \pm 1.8 \mathrm{pg} / \mathrm{ml}$, are elevated compared to both $4.7 \pm 2.2 \mathrm{pg} / \mathrm{ml}$ at D.28 ( $p=0.01)$ and $3.0 \pm 1.9 \mathrm{pg} / \mathrm{ml}$ at D.42 ( $p=0.003)$. In NLR blood, there is a trend toward increasing RANTES levels with storage time, $12.0 \pm 1.6$ $\mathrm{pg} / \mathrm{ml}$ at D. 1 compared to $15.8 \pm 0.7 \mathrm{pg} / \mathrm{ml}$ at D.42 ( $p=0.06)$. NLR blood RANTES levels are increased compared to LR blood at both D.28, $14.8 \pm 1.2 \mathrm{vs} .4 .7 \pm 2.2 \mathrm{pg} / \mathrm{ml}$, respectively, $(p=0.004)$, and D.42, $15.8 \pm 0.7$ vs. $3.0 \pm 1.9 \mathrm{pg} / \mathrm{ml}$, respectively, $(p<0.001)$. 
Angiogenin-Angiogenin levels in the plasma fraction of pRBCs are shown in Fig. 2c. Collectively, angiogenin levels were increased in NLR blood, $44.2 \pm 3.7 \mathrm{pg} / \mathrm{ml}$, vs. LR blood, $0 \mathrm{pg} / \mathrm{ml}$ (undetectable, $p<0.001$ ), and elevated in NLR blood compared to LR blood at each time point, $52.6 \pm 4.4$ vs. $0 \mathrm{pg} / \mathrm{ml}$ at D. $1(p<0.001), 42.7 \pm 7.1 \mathrm{vs.} 0 \mathrm{pg} / \mathrm{ml}$ at D.28 $(p<0.001)$, and $37.2 \pm 6.5 \mathrm{vs} .0 \mathrm{pg} / \mathrm{ml}$ at D.42 ( $p<0.001)$. There was no difference observed in angiogenin levels with storage time in NLR blood, with a trend of decreasing concentration, $52.6 \pm 4.4 \mathrm{pg} / \mathrm{ml}$ at D. 1 vs. $37.2 \pm 6.5 \mathrm{pg} / \mathrm{ml}$ at D. $42(p=0.08)$.

TNF- $\alpha-T N F-\alpha$ levels in the plasma fraction of pRBCs are shown in Fig. 2d. No differences were observed with storage for LR blood, $1.1 \pm 0.5 \mathrm{pg} / \mathrm{ml}$ at D. $1 \mathrm{vs.} 2.0 \pm 0.9 \mathrm{pg} /$ $\mathrm{ml}$ at D.42, and for NLR blood, $1.0 \pm 0.4 \mathrm{pg} / \mathrm{ml}$ at D. 1 vs. $2.0 \pm 0.7 \mathrm{pg} / \mathrm{ml}$ at D. 42 (both $p=$ NS). TNF- $a$ concentrations showed no difference between LR and NLR blood at any time point.

EGF-EGF levels in the plasma fraction of pRBCs are shown in Fig. 2e. In LR blood, there was no storage effect on levels, $216.4 \pm 3.8 \mathrm{pg} / \mathrm{ml}$ at D. 1 vs. $207.3 \pm 7.2 \mathrm{pg} / \mathrm{ml}$ at D. 42 ( $p=$ NS). In NLR blood, EGF levels increase with storage time. D.1 levels, $241.1 \pm 13.1 \mathrm{pg} / \mathrm{ml}$, increase by D.28 to $801.1 \pm 130.3 \mathrm{pg} / \mathrm{ml}(p=0.003)$, and further increase to $1,436.4 \pm 238.6$ $\mathrm{pg} / \mathrm{ml}$ at D.42 ( $p=0.001)$. NLR blood EGF levels are increased compared to LR blood at both D. $28,801.1 \pm 130.3$ vs. $216.8 \pm 13.8 \mathrm{pg} / \mathrm{ml}$, respectively ( $p=0.002$ ), and at D.42, $1,436.4 \pm 238.6$ vs. $207.3 \pm 7.2 \mathrm{pg} / \mathrm{ml}$, respectively ( $p<0.001)$.

PDGF-BB-PDGF-BB levels in the plasma fraction of pRBCs are shown in Fig. 2f. In LR blood, PDGF-BB levels decrease with storage time, $7.3 \pm 0.3 \mathrm{pg} / \mathrm{ml}$ at D. 1 vs. $6.4 \pm 0.1 \mathrm{pg} / \mathrm{ml}$ at D.42 ( $p=0.01)$. In NLR blood, PDGF-BB levels increase with storage time. D.1 levels, $34.7 \pm 9.7 \mathrm{pg} / \mathrm{ml}$, increase by D. 28 to $73.6 \pm 2.3 \mathrm{pg} / \mathrm{ml}(p=0.005)$, and further increase to $76.5 \pm 1.7 \mathrm{pg} / \mathrm{ml}$ at D.42 ( $p=0.003)$. NLR blood PDGF-BB levels are increased compared to LR blood at all time points, $34.7 \pm 9.7$ vs. $7.3 \pm 0.3 \mathrm{pg} / \mathrm{ml}$, respectively, at D.1 ( $p=0.02$ ), $73.6 \pm 2.3$ vs. $6.6 \pm 0.2 \mathrm{pg} / \mathrm{ml}$, respectively, at D. 28 ( $p<0.001$ ), and $76.5 \pm 1.7$ vs. $6.4 \pm 0.1 \mathrm{pg} /$ $\mathrm{ml}$, respectively, at D.42 $(p<0.001)$.

\section{Migration of Pan02 Cells Treated with Gefitinib}

Based on the differential expression of EGF in stored pRBCs, cellular migration of Pan02 cells was measured, and differences of media treated with the plasma fraction of pRBCs were compared when also treated with the EGF inhibitor gefitinib (Fig. 3). Exposure of Pan02 cells to D.1 LR, D.1 NLR, or D.42 LR blood had similar migration with or without treatment with gefitinib. However, migration of Pan02 cells treated with D.42 NLR blood was significantly reduced when treated with gefitinib, $245.9 \pm 11.2$ cells/high-powered field (hpf) in D.42 NLR blood vs. 164.6 \pm 10.6 cells/hpf in D.42 NLR blood plus gefitinib $(p<0.001)$.

\section{Migration and Proliferation of Pan02 Cells Treated with Imatinib}

Based on the differential expression of PDGF-BB in stored pRBCs, cellular migration of Pan02 cells exposed to the plasma fraction of pRBCs was measured to determine any effect of treatment with the PDGF inhibitor imatinib. In Pan02 cells treated with D.1 or D.42, LR or NLR blood, additional treatment with imatinib did not decrease cellular migration (Fig. 4a). In fact, treatment with imatinib showed increased migration in cells treated with D.1 LR (96.2 \pm 6.4 in untreated vs. $153.5 \pm 15.0$ cells/hpf in treated, $p=0.002)$, D.1 NLR (148.8 \pm 16.2 in untreated vs. $236.5 \pm 17.5 \mathrm{cells} / \mathrm{hpf}$ in treated, $p=0.03)$, and D.42 LR (59.9 \pm 8.6 in untreated vs. $138.2 \pm 8.8 \mathrm{cells} / \mathrm{hpf}$ in treated, $p<0.001)$. These results led us to test the effects of imatinib treatment on Pan02 cell proliferation for cells exposed to the plasma fraction of pRBCs (Fig. 4b). Exposure of Pan02 cells treated with D.1 LR, D.1 NLR, and D.42 LR 
blood had similar proliferation with or without treatment with imatinib. However, proliferation of cells treated with D.42 NLR blood was significantly reduced when additionally treated with imatinib (181.1 $\pm 1.5 \%$ over control (DMEM alone) in untreated vs. $157.5 \pm 2.1 \%$ over control in treated, $p<0.001)$.

\section{Discussion}

Multiple factors were identified in pRBCs that have tumorigenic properties and may augment tumor growth and progression. Of the six factors observed in stored $\mathrm{pRBCs}$, angiogenin, TNF- $a$, and RANTES do not accumulate with storage, but are elevated in fresh blood. These factors may contribute to the observed detrimental effect of tumor progression with the transfusion of fresh blood as previously demonstrated in an immunocompetent model of pancreatic adenocarcinoma. ${ }^{9}$ Additionally, all mediators, with the exception of TNF-a, are significantly reduced with leukocyte reduction, indicating a potential role in removing white blood cells in the treatment of cancer patients, although it remains undetermined in clinical studies whether LR blood improves outcomes compared to NLR blood. $^{22}$

Tumor infiltration with macrophages has been shown to negatively correlate with outcomes in about $80 \%$ of solid tumors. ${ }^{26-28}$ Recently, neutrophils have also been implicated as important effector cells and are integral in the angiogenic switch. ${ }^{29}$ MCP-1, RANTES, TNF$a$, and PDGF are all potent immune chemoattractants, especially for macrophages and neutrophils, which may lead to possible detrimental effects by providing these factors through transfusions of blood products. Additionally, upregulation of RANTES and MCP-1 has been shown in breast and cervical cancer, and assists in angiogenesis. ${ }^{30-32}$ TNF-a has also been shown to be a cancer-promoting cytokine in breast cancer, important in the endothelial-to-mesenchymal transition. ${ }^{32}$

Elevated levels of angiogenin, one of the most potent angiogenic factors, is associated with aggressive disease in many cancers including gastric, pancreatic, colorectal, urothelial, brain, melanoma, and non-Hodgkin lymphoma. ${ }^{33,34}$ Angiogenin is present in NLR blood and does not change with storage time. Leukocyte reduction eliminates angiogenin from stored pRBCs.

Overexpression of EGF and its receptor have been linked to poorer outcomes in lung, colon, breast, pancreas, bladder, and head and neck cancer. ${ }^{35,36} \mathrm{EGF}$ is a strong mitogen, increasing proliferation and survival, and is an angiogenic factor. ${ }^{36}$ Our study reveals that EGF levels increase with storage time in NLR blood, and these increases in EGF are abrogated with leukocyte reduction. In vitro treatment with gefitinib of Pan02 cells that are exposed to D.42 NLR blood, which correlates to a blood product that has the highest levels of EGF, attenuated cellular migration.

PDGF-BB is involved in angiogenesis, lymphangiogenesis, acts as a mitogen, and is elevated in some forms of cancer. ${ }^{37}$ PDGF levels in blood increase with storage time in NLR blood, not in LR blood. In vitro treatment with a PDGF inhibitor of Pan02 cells exposed to D.42 NLR blood, which correlates to a blood product that has the highest levels of EGF, attenuated cellular proliferation but not migration.

\section{Conclusion}

These data demonstrate the presence of pro-cancer cytokines and growth factors in $\mathrm{pRBCs}$, which are either present at the highest level in fresh blood or accumulate significantly during storage. Although the negative effects of blood transfusion are likely multi-factorial, the tumorigenic mediators identified in the acellular fraction of $\mathrm{pRBCs}$ may represent possible 
therapeutic targets to offset negative effects of transfusion on clinical outcomes. Further examination of pretreatment of blood products or patients with specific inhibitors such as gefitinib and imatinib is warranted. As many of these pro-cancer cytokines were reduced by prestorage leukocyte reduction, this practice is likely beneficial, although it has not been demonstrated in current trials examining colorectal cancers. ${ }^{22}$ Together, these data reiterate the importance of limiting the use of blood products in patients with underlying malignancies, and further strategies to avoid transfusion should be pursued.

\section{Acknowledgments}

This work was supported in part by the American Cancer Society, grant \# MSRG-09-034-01-CCE.

\section{References}

1. Yeh JJ, Gonen M, Tomlinson JS, Indrees K, Brennan MF, Fong Y. Effect of blood transfusion on outcome after pancreaticoduodenectomy for exocrine tumor of the pancreas. Br J Surg. 2007; 94:466-472. [PubMed: 17330243]

2. Park SJ, Kim SW, Jang JY, Lee KU, Park YH. Intraoperative transfusions: Is it a real prognostic factor of periampullary cancer following pancreatoduodenectomy? World J Surg. 2002; 26:487492. [PubMed: 11910485]

3. Blumberg N, Heal J, Chuang C, Murphy P, Agarwal M. Further evidence supporting a cause and effect relationship between blood transfusion and earlier cancer recurrence. Ann Surg. 1988; 207:410-415. [PubMed: 3355265]

4. Marsh J, Donnan PT, Hamer-Hodges DW. Association between transfusion with plasma and the recurrence of colorectal carcinoma. Br J Surg. 1990; 77:623-626. [PubMed: 2383726]

5. Wobbes T, Joosen KH, Kuypers HH, Beerthuizen GI, Theeuwes GM. The effect of packed cells and whole blood transfusions on survival after curative resection for colorectal carcinoma. Dis Col Rect. $1989 ; 32: 743-748$.

6. Blajchman MA. The clinical benefits of leukoreduction of blood products. J Trauma. 2006; 60:S83S90. [PubMed: 16763486]

7. Benson D, Barnett CC Jr. Perioperative blood transfusions promote pancreas cancer progression. J Surg Res. 2011; 166:275-279. [PubMed: 20828757]

8. Vamvakas EC, Blajchman MA. Transfusion-related immunomodulation (TRIM): An update. Blood Rev. 2007; 21:327-348. [PubMed: 17804128]

9. Barnett CC Jr, Beck AW, Holloway SE, Kehler M, Schluterman MK, Brekken RA, Fleming JB, Silliman CC. Intravenous delivery of the plasma fraction of stored packed red cells promotes pancreatic cancer growth in immunocompetent mice. Cancer. 2010; 116:3862-3874. [PubMed: 20564095]

10. Benson DD, Kelher MR, Meng X, Fullerton DA, Lee JH, Silliman CC, Barnett CC Jr. Genderspecific transfusion affects tumor-associated neutrophil: macrophage rations in murine pancreatic adenocarcinoma. J Gastrointest Surg. 2010; 14:1560-1565. [PubMed: 20835771]

11. Moore PK, Benson D, Kelher M, Moore EE, Fragoso M, Silliman CC, Barnett CC Jr. The plasma fraction of stored erythrocytes augments pancreas cancer metastasis in male versus female mice. $\mathrm{J}$ Surg Res. 2010; 164:23-27. [PubMed: 20828763]

12. Silliman CC, Ambruso DR, Boshkov LK. Transfusion-related acute lung injury. Blood. 2005; 105:2266-2273. [PubMed: 15572582]

13. Moore FA, Moore EE, Sauaia A. Blood transfusion: An independent risk factor for postinjury multiple organ failure. Arch Surg. 1997; 132:620-625. [PubMed: 9197854]

14. Sillman CC, Boshkov LK, Mehdizadehkashi Z, Elzi DJ, Dickey WO, Podlosky L, Clarke G, Ambruso DR. Transfusion-related acute lung injury: Epidemiology and a prospective analysis of etiologic factors. Blood. 2003; 101:454-462. [PubMed: 12393667]

15. Biffl WL, Moore EE, Offner PJ, Ciesla DJ, Gonzalez RJ, Sillman CC. Plasma from aged stored red blood cells delays neutrophil apoptosis and primes cytotoxicity: Abrogation by poststorage washing but not prestorage leukoreduction. J Trauma. 2001; 50:426-432. [PubMed: 11265021] 
16. Silliman CC, Voelkel NF, Allard JD, Elzi DJ, Tuder RM, Johnson JL, Ambruso DR. Plasma and lipids from stored packed red blood cells cause acute lung injury in an animal model. J Clin Invest. 1998; 101:1458-1467. [PubMed: 9525989]

17. Silliman CC, Clay KL, Thurman GW, Johnson CA, Ambruso DR. Partial characterization of lipids that develop during the routine storage of blood and prime the neutrophil NADPH oxidase. J Lab Clin Med. 1994; 124:684-694. [PubMed: 7964126]

18. Offner PJ, Moore EE, Biffl WL, Johnson JL, Sillman CC. Increased rate of infection associated with transfusion of old blood after severe injury. Arch Surg. 2002; 137:711-717. [PubMed: 12049543]

19. Romano G, Mastroianni C, Bancone C, Della Corte A, Galdieri N, Nappi G, De Santo LS. Leukoreduction program for red cell transfusions in cardiac surgery: association with reduced acute kidney injury and in-hospital mortality. J Thorac Cardiovasc Surg. 2010; 140:188-195. [PubMed: 20416894]

20. Bordin JO, Heddle NM, Blajchman MA. Biologic effects of leukocytes present in transfused cellular blood products. Blood. 1994; 84:1703-1721. [PubMed: 8080981]

21. Vamvakas EC, Blajchman MA. Prestorage versus poststorage white cell reduction for the prevention of the deleterious immunomodulatory effects of allogenic blood transfusion. Transfus Med Rev. 2000; 14:23-33. [PubMed: 10669938]

22. Bilgin YM, Brand A. Transfusion-related immunomodulation: a second hit in an inflammatory cascade? Vox Sang. 2008; 95:261-271. [PubMed: 19138255]

23. Houbiers JG, Brand A, van de Watering LM, Hermans J, Verwey PJ, Bijnen AB, Pahlplatz P, Eeftinck Schattenkerk M, Wobbes T, de Vries JE. Randomized control trial comparing transfusion of leukocyte-depleted or buffy-coat-depleted blood in surgery for colorectal cancer. Lancet. 1994; 344:573-578. [PubMed: 7914960]

24. Van de Watering LM, Brand A, Houbiers JG, Klein-Kranenberg WM, Hermans J, van de Velde C. Cancer Recurrance and Blood transfusion study group. Perioperative blood transfusions, with or without allogenic leukocytes, relate to survival, not to cancer recurrence. Br J Surg. 2001; 88:261266. [PubMed: 11167878]

25. Technical Manual. American Association of Blood Banks; Bethesda: 2003.

26. Coussens LM, Werb Z. Inflammation and cancer. Nature. 2002; 420:860-867. [PubMed: 12490959]

27. Pollard JW. Tumour-educated macrophages promote tumour progression and metastasis. Nat Rev Cancer. 2004; 4:71-78. [PubMed: 14708027]

28. Bingle L, Brown NJ, Lewis CE. The role of tumour-associated macrophages in tumor progression: implications for new anticancer therapies. J Pathol. 2002; 196:254-265. [PubMed: 11857487]

29. Nozawa H, Chui C, Hanahan D. Infiltrating neutrophils mediate the initial angiogenic switch in a mouse model of multistage carcinogenesis. Proc Natl Acad Sci USA. 2006; 103:12493-12498. [PubMed: 16891410]

30. Azenshtein E, Luboshits G, Shina S, Neumark E, Shahbazian D, Weil M, Wigler N, Keydar I, BenBaruch A. The CC chemokine RANTES in breast carcinoma progression: regulation of expression and potential mechanisms of promalignant activity. Cancer Res. 2002; 62:1093-1102. [PubMed: 11861388]

31. Niwa Y, Akamatsu H, Niwa H, Sumi H, Ozaki Y, Abe A. Correlation of tissue and plasma RANTES levels with disease course in patients with breast or cervical cancer. Clin Cancer Res. 2001; 7:285-289. [PubMed: 11234881]

32. Soria G, Ofri-Shahak M, Haas I, Yaal-Hahoshen N, Trejo-Leider L, Leibovich-Rivkin T, Weitzenfield P, Meshel T, Shabtai E, Gutman M, Ben-Baruch A. Inflammatory mediators in breast cancer: Coordinated expression of TNFalpha \& IL-1beta with CCL2 \& CCL5 and effects on epithelial-to-mesenchymal transition. BMC Cancer. 2011; 11:130.10.1186/1471-2407-11-130 [PubMed: 21486440]

33. Shimoyama S, Gansauge F, Gansauge S, Negri G, Oohara T, Beger HG. Increased angiogenin expression in pancreatic cancer is related to cancer aggressiveness. Cancer Res. 1996; 56:27032706. [PubMed: 8665497] 
34. Fang S, Repo H, Joensuu H, Orpana A, Salven P. High serum angiogenin at diagnosis predicts for failure on long-term treatment response and for poor overall survival in non-Hodgkin lymphoma. Eur J Cancer. 201110.1016/j.ejca.2011.02.018

35. Shi X, Friess H, Kleef J, Ozawa F, Buchler MW. Pancreatic cancer: factors regulating tumor development, maintenance, and metastasis. Pancreatology. 2001; 1:517-524. [PubMed: 12120231]

36. Grandis JR, Sok JC. Signaling through the epidermal growth factor receptor during the development of malignancy. Pharmacol Ther. 2004; 102:37-46. [PubMed: 15056497]

37. Cao R, Bjorndahl MA, Religa P, Clasper S, Garvin S, Galter D, Meister B, Ikomi F, Tritsaris K, Dissing S, Ohhashi T, Jackson DG, Cao Y. PDGF-BB induces intratumoral lymphan-giogenesis and promotes lymphatic metastasis. Cancer Cell. 2004; 6:333-345. [PubMed: 15488757] 
a

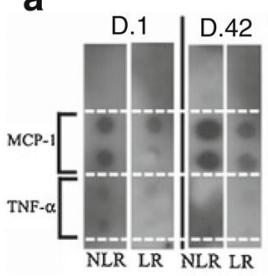

b

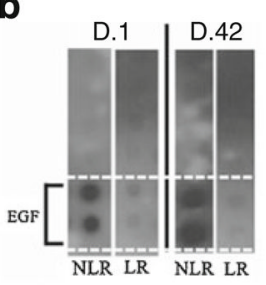

$\mathbf{C}$

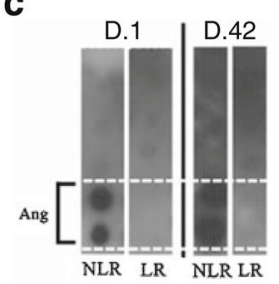

d

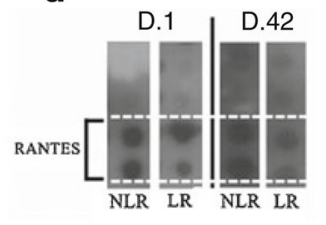

e

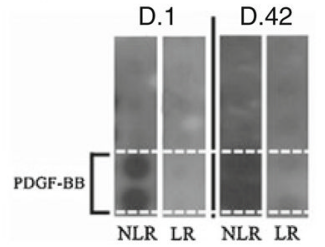

Fig. 1.

Screening ChemiArray analysis from the day 1 (D.1) and day $42(D .42)$, leukoreduced (LR) or nonleukoreduced $(N L R)$, plasma fraction of stored pRBCs. Each dot in duplicate represents detection of a specific cytokine or growth factor. a Columns from ChemiArray analysis from D.1 and D.42, NLR and LR, blood showing increased expression of MCP-1 and TNF-a in duplicate. Solid black line separates two trials. The same experiments run with ChemiArray show elevated expression of EGF (b), angiogenin (Ang, c), RANTES (d), and PDGF-BB (e) 

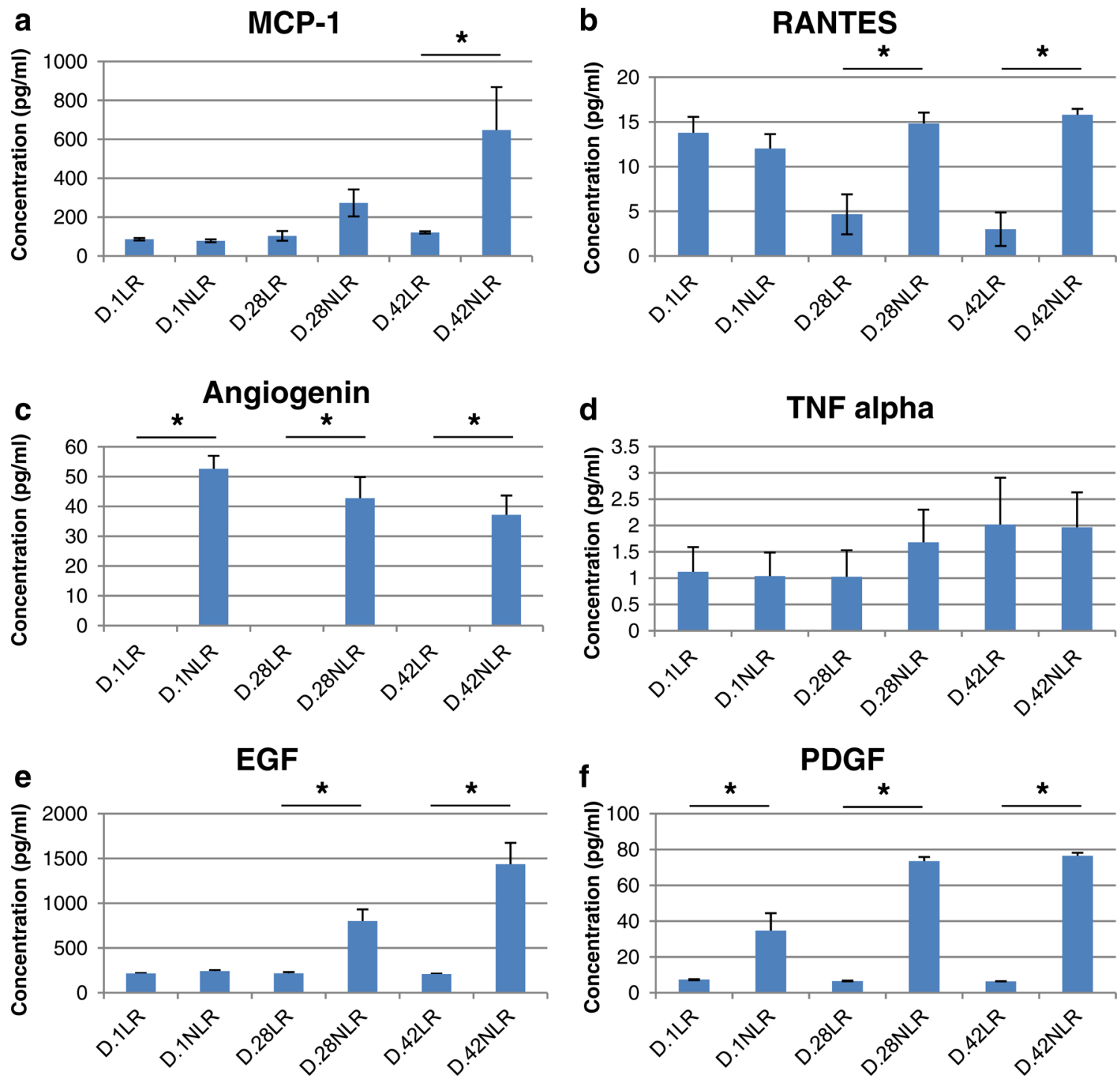

Fig. 2.

Quantitative determination of the effect of leukoreduction $(L R)$ and storage time on protein concentrations identified by ChemiArray analysis were performed using enzyme-linked immunosorbent assay. a MCP-1 levels increase with storage time from day 1 (D.1) to day 42 $(D .42)$ in LR $(p<0.01)$ and markedly increase in nonleukoreduced $(N L R)$ blood $(p=0.02)$. There is also higher levels of MCP-1 in D.42 NLR blood compared to D.42 LR blood (* $p=0.05)$. b RANTES levels decrease in LR blood after D.1 $(p=0.01)$. Levels trend toward increasing levels of RANTES in NLR blood ( $p=0.06)$. Compared to LR blood, NLR blood has higher RANTES levels at D.28 $(* p<0.01)$, and D.42 $(* p<0.001)$. c Angiogenin levels in NLR blood have a trend toward decreasing levels with storage time $(p=0.08)$. NLR has higher angiogenin levels compared to LR blood, where LR decreases angiogenin levels to undetectable (all * $p<0.001$ ). d TNF-a levels are not different with either storage time or LR. e EGF levels increase with storage time in NLR blood from D. 1 to D.42 ( $p=0.001)$. No change of EGF levels with storage time was observed in LR blood. Compared to LR blood, NLR blood has higher EGF levels at D.28 $(* p<0.01)$ and D.42 $(* p<0.001)$. f PDGF-BB levels decrease with storage time in LR blood from D.1 to D.42 $(p=0.01)$. Level increases 
with storage time in NLR blood ( $p<0.01)$. Compared to LR blood, NLR blood has higher PDGF-BB levels at D.1 (*p=0.02), D.28 $(* p<0.01)$, and D.42 $(* p<0.001)$ 


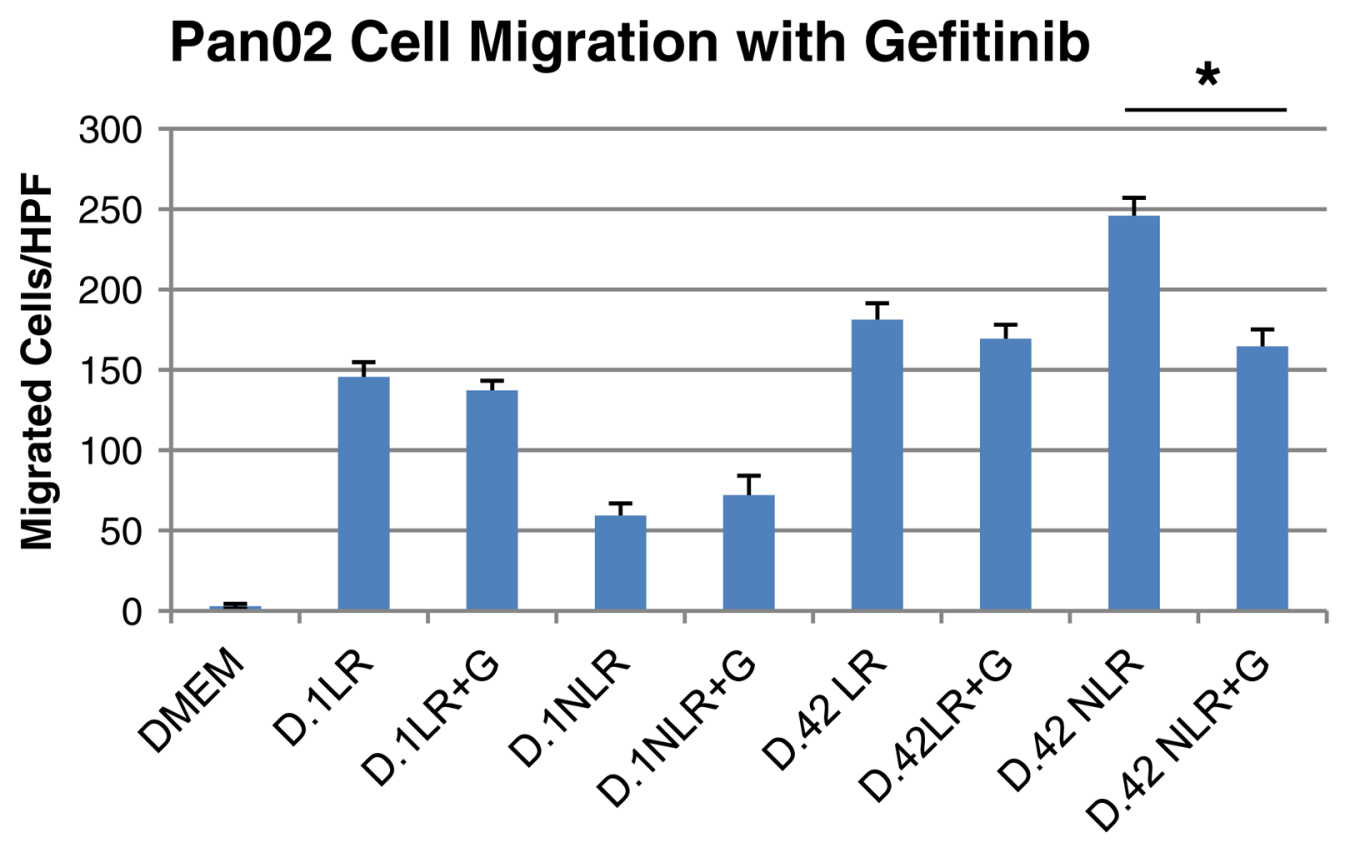

Fig. 3.

Pan02 cell migration when treated with the plasma fraction of stored pRBCs with or without gefitinib $(G)$ was significantly decreased in cells exposed to "outdate," D.42 NLR blood $(* p<0.001)$. Treatment with gefitinib did not affect Pan02 migration in cells exposed to “outdate” D.42 LR or any D.1 blood. HPF high-powered field, DMEMDulbecco's minimal essential medium 

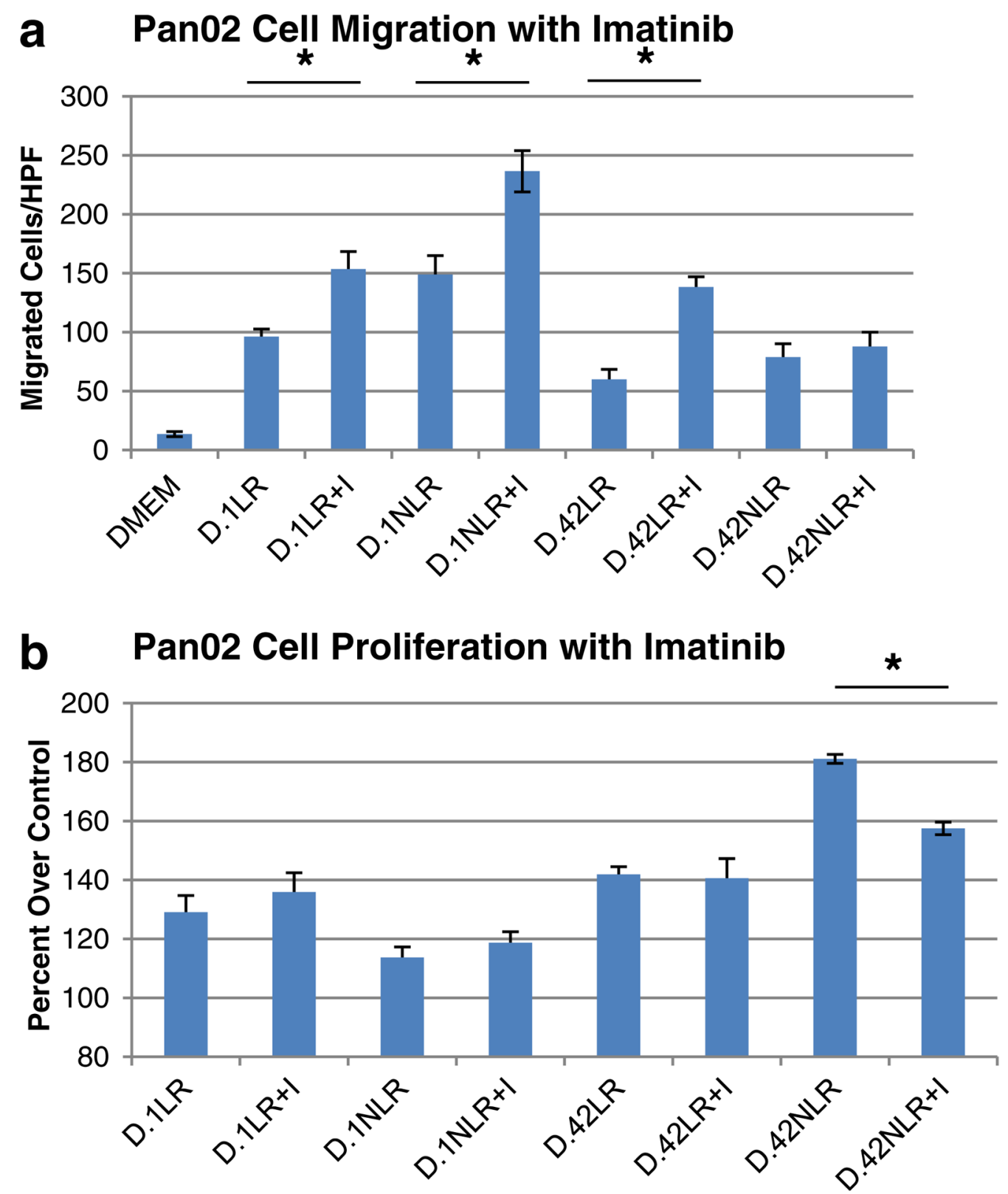

Fig. 4.

a Pan02 cell migration in cells treated with the plasma fraction of stored pRBCs with or without imatinib $(I)$. Treatment with imatinib increased cell migration in cells treated with D.1 LR $(* p<0.01)$ and NLR (* $p=0.03)$, as well as D.42 LR blood $(* p<0.001)$. b Pan02 cell proliferation in cells treated with the plasma fraction of stored $\mathrm{pRBCs}$ with or without imatinib reveals imatinib decreased cell proliferation in cells treated with D.42 NLR blood ( $p<0.001)$. HPF high-powered field, DMEM Dulbecco's minimal essential medium, percent over control (DMEM only) 